\title{
Effect of Oral Administration of Aqueous Whole Extract of Cassytha Filiformis on Haematograms and Plasma Biochemical Parameters in Rats
}

\author{
Hausatu M. Babayi, B.Techa, Joseph, J. I. Udeme Profa, Joseph A. Abalaka Profb, \\ Joseph I. Okogun Profc, O. A. Salawu, Ph.Dd, David D. Akumka MScd, Adamu, HNDd, \\ Sunday S. Zarma, ONDd, Bulus B. Adzu MScd, Sabo S. Abdulmumuni BScd, Kolo Ibrahime, \\ Baba B. Elisha $H N D^{e}$, Samuel S. Zakariys, HNf, Uford S. Inyang, PhDd
}

\author{
aDepartment of Microbiology \\ bDepartment of Biochemistry, Federal University of Technology, Minna, Niger State, Nigeria \\ cDepartment of Medicinal Plant Research and Traditional Medicine \\ dDepartment of Pharmacology and Toxicology \\ eDiagnostic Clinic \\ fAnimal Facility Centre, National Institute for Pharmaceutical Research and Development, Idu, Abuja
}

\begin{abstract}
Introduction: We evaluated the sub-chronic toxicity of the aqueous herbal extract prepared from Cassytha filiformis and administered daily for 28 days at dose levels $\left(250,500\right.$, and $1000 \mathrm{mg} / \mathrm{kg}$ bw) in male wistar albino rats. The $\mathrm{LD}_{50}$ of the aqueous extract was determined.

Methods: The effects on body weights, organ weights, and certain haematological and plasma biochemical parameters were measured as indices of organ toxicity.

Results: The aqueous extract did not affect plasma glutamate oxaloacetate transaminase (GOT) and glutamate pyruvate transaminase (GPT); however, a significant reduction in alkaline phosphatase (ALP) level occurred in all the treated groups. It also did not affect the electrolytes $(\mathrm{Na}+, \mathrm{Cl}-$ and $\mathrm{K}+)$, total and direct bilirubin, creatinine, and glucose level. The aqueous extract elicited hypercholesterolaemic effects, but it did not affect the Hb, WBC, RBC, PVC, platelets, MCH, MCHC, MCV levels and differential counts (lympocytes, neutrophils, monocytes, eosinophils and basophils). It also reduced the body weight gain and absolute weight of the kidneys. The relative weights of the heart and lungs in some animal groups were equally reduced. The acute toxicological evaluation of the plant extract revealed an oral $\mathrm{LD}_{50}$ value greater than $500 \mathrm{mg} / \mathrm{kg}$ bw.
\end{abstract}

Conclusion: This study suggests that aqueous extract of $C$. filiformis administered at normal therapeutic doses is not likely to produce severe toxic effects on some organs or haematological and biochemical indices in rats.

Keywords: cassytha filiformis, organ weight, haematology, serum biochemistry, hypercholesterolaemic

Notes: There was no outside funding of any kind used for this study.

Acknowledgements: Authors are thankful to the National Institute for Pharmaceutical Research and Development, NIPRD, Idu, Abuja, Nigeria for providing the facility for the study.

Corresponding Author: Hausatu Moh'd. Babayi, Department of Microbiology, P.M.B 65, Federal University of Technology, Minna, Niger State, Nigeria. Email: acadbabayi@yahoo.com 


\section{INTRODUCTION}

Herbal remedies are commonly employed in developing countries to treat various diseases. This practice is an alternative to compensate for some perceived deficiencies in orthodox pharmacotherapy [4]. There is limited scientific evidence regarding the safety and efficacy to support the continued therapeutic application of these herbal remedies. Their utilization is often based on long-term clinical experience. With the upsurge in the use of herbal remedies, there is need for a thorough scientific evaluation of these medicinal plants. This will help to validate or invalidate their folkloric uses [17].

Cassytha filiformis is a plant used for various ethnomedical purposes in Nigeria. Evaluation of this plant is based on its traditional use by a substantial population in the Northern part of Nigeria for the treatment of diseases such as diabetes. In the Northern part of Nigeria, the plant (stem and leaves) is boiled with red potash in water and administered for varying lengths of time to treat Diabetes mellitus [6]. This rootless parasitic plant is also administered for the relief of ulcer, veneral discharges, haemorrohoids, cough, and other things [13,2,9].

To the best of our knowledge, there is no record in the literature of the toxicity profile of Cassytha filiformis. The subacute and subchronic toxicity data may be required to predict the safety and effects of long term exposure to a particular medicinal plant [4]. Our study was therefore undertaken to determine the subchronic toxicity profile of Cassytha filiformis on rats.

\section{MATERIALS AND METHODS}

\section{Experimental animals}

We used mice (19 to $30 \mathrm{~g}$ ) for the acute toxicity evaluation and adult Wistar male rats (140-250 g) for the subchronic toxicity profiling. The Animal Facility Centre (AFC), National Institute for Pharmaceutical Research Development (NIPRD), provided the animals. They were fed ad libitum with standard feed (Ladokun Feeds, Ibadan, Nigeria) and allowed free access to water. They were also maintained under standard conditions of humidity (40-60\%), temperature $\left(20-22^{\circ} \mathrm{C}\right)$, and a 12 hour light and darkness cycle. We acclimated the animals to housing conditions for one week prior to the commencement of the study. The animals were handled in accordance with the WHO good Laboratory practice (GLP) regulations of 1998 [16]. Principles of laboratory animal care were also followed throughout the study [13].

\section{Protocol}

Whole parts (stems and leaves) of Cassytha filiformis are an antidiabetic plant obtained from Mal. Garba, a local herbalist in Zaria, Kaduna State, Nigeria. The plant was authenticated at the Herbarium Department of NIPRD. The plant parts were then dried at room temperature $\left(28 \pm 2^{\circ} \mathrm{C}\right)$ for two weeks. The dried sample was milled into fine powder. The sample was prepared in the same manner as traditional healers: $100 \mathrm{~g}$ of dried whole plant and $2.00 \mathrm{~g}$ of red potash (lake salt) were refluxed in $500 \mathrm{ml}$ of sterile distilled water for 6 hours. The mixture was filtered with Whatman filter paper No 1 and the filtrate was concentrated to dryness at $50^{\circ} \mathrm{C}$ with a rotary evaporator. The dried aqueous extract was stored in airtight sterile containers and refrigerated until use. We determined the $\mathrm{LD}_{50}$ value for mice using Lorke's (1983) method [11]. The body weight of each rat was assessed using a sensitive balance during the acclimatized period; once before commencement of dosing, once weekly during the dosing period, and once on the day of sacrifice.

During the four weeks of dosing, all the animals were observed daily for clinical signs and mortality patterns; they were observed once before dosing, immediately after dosing, and up to 3 hours after dosing.

24 rats, selected by stratified randomisation, were used for the sub-chronic toxicity study. They were divided into four groups of six. The first group served as a control and were given equivalent volumes of water while the remaining three groups were orally administered 250, 500, and $1000 \mathrm{mg} / \mathrm{kg}$ bw of aqueous whole extract of Cassytha filiformis, respectively, for 28 days. The selection of the dose range was based on a previous study on the antidiabetic activity of aqueous extract of Cassytha filiformis on alloxan induced diabetic rats (data not shown). The first day of administration was taken as $\mathrm{D}_{0}$ while the day of sacrifice was designated as $\mathrm{D}_{28}$. We observed daily the physical appearances and activities of the rats. After 28 days of drug exposure, the animals were weighed and exsanguinated under chloroform anaesthesia. Blood samples were drawn from the heart of each sacrificed animal. For blood parameter studies, we obtained blood samples of the six animals in each group. The samples were collected in plastic test tubes and allowed to stand for 3 hours to ensure complete clotting. The clotted blood samples were centrifuged at $3000 \mathrm{rpm}$ for $10 \mathrm{mins}$, and clear serum samples were aspirated off and stored frozen. The biochemical parameters, Glutamate oxaloacetate transminase (GOT, AST), glutamate pyruvate transminase (GPT, ALT), alkaline phosphatase (ALP), bilirubin, urea, cholesterol, creatinine, sodium, chloride, and others, were colorimetrically determined by employing the standard ready to use kits and methods of Human Gesellschfat for Biochemical and Diagnosis MBH, Germany. During the course of our investigation, we strictly followed the manufacturer's instructions for each biochemical parameter.

The Haematological tests were carried out in an ethylenediaminetetra-acetic acid (EDTA) anticogaulated blood. Haemoglobin $\mathrm{Hb}$ ) concentration was analysed by the cyanomethaemoglobin method, packed cell volume (PCV) by micro-method and white blood cell (WBC) (total and differential) and platelet counts by visual methods [5]. The mean cell haemoglobin concentration (MCHC) was calculated by dividing $\mathrm{Hb}$ by PCV.

Different organs (namely, heart, spleen, liver, lungs, kidneys, and testes) were carefully disserted and their absolute weights were determined. The relative organ weight of each animal was then calculated as follows:

$$
\begin{aligned}
& \text { Relative organ } \\
& \text { weight }
\end{aligned}=\frac{\text { Absolute organ weight }(\mathrm{g})}{\text { Body weight of rat on sacrificed day }(\mathrm{g})} \times \frac{100}{1}
$$


Data generated are expressed as means \pm SD. The statistical comparisons were performed using the Duncan multiple range test. The results were considered statistically significant at $\mathrm{P}<0.05$.

\section{Results}

The animals did not experience death or any sign of physical toxicity throughout the period of study. There were no changes in the nature of stool, urine, and eye color in any of the animals. Animals did not exhibit diarrhoea, haematuria, restlessness, uncoordinated muscle movements, and respiratory or cardiovascular distress during the study period. The results reveal that all the doses of the extract $(10-5000 \mathrm{mg} / \mathrm{kg} \mathrm{bw}$ ) did not produce any demonstrable acute toxic effect or death in all the groups of mice.

Compared to the control group, there was a significant reduction $(\mathrm{P}<0.05)$ in fluid consumption in the group that received $1000 \mathrm{mg} / \mathrm{kg} \mathrm{bw}$, and there was a significant increase $(\mathrm{P}<0.05)$ in the volume of fluid ingested by the animals that received 250 and $500 \mathrm{mg} / \mathrm{kg}$ bw. Food consumption was not significantly affected $(\mathrm{P}>0.05)$ by exposure to the extract.

All treated groups showed increases in body weight over the period of the experiment. However, the control group's percentage increases in mean body weights were significantly higher $(\mathrm{P}<0.05)$ than the treated groups. The treated groups showed a more significant reduction $(\mathrm{P}<0.05)$ in the absolute weight of the kidneys than the control group. There were no significant differences $(\mathrm{P}>0.05)$ in liver, spleen, testes, and kidneys expressed as percent of body weight between the control and the treated groups at termination of the experiment. However, there was a significant difference $(\mathrm{P}<0.05)$ in the relative organ weights of the lungs and heart between the drug exposed groups and the control group (Table 1).

Results of the haematological studies are presented in Table 2 and Table 3. The data showed that all the haematological parameters for the control rats were not significantly different $(\mathrm{P}<0.05)$ from those treated with the aqueous whole extract of Cassytha filiformis.

Table 4 provides the plasma biochemical data at termination of the study. No significant changes $(\mathrm{P}>0.05)$ were observed in the clinical biochemical parameters $\left(\mathrm{Cl}^{-}, \mathrm{Na}^{+}, \mathrm{K}^{+}\right.$, creatinine, total and direct bilirubin, GOT, GPT, and glucose) measured between the treated groups and the control. There was no significant difference $(\mathrm{P}>0.05)$ in the urea level between the control group and the groups that received 250 and $1000 \mathrm{mg} / \mathrm{kg} \mathrm{bw}$, but the urea level of the group treated with $500 \mathrm{mg} / \mathrm{kg}$ bw was significantly reduced $(\mathrm{P}>0.05)$ when compared to other groups.

In all dose levels tested, the alkaline phosphatase (ALP) levels were significantly decreased, but this decrease did not appear to be dose dependent. However, one daily administration of extract for 28 days resulted in significantly increased levels of cholesterol $(\mathrm{P}<0.05)$.

\section{DISCUSSION}

The acute toxicological evaluation of the herbal extract revealed an oral $\mathrm{LD}_{50}$ value greater than $500 \mathrm{mg} / \mathrm{kg}$ bw. Therefore, the medicinal plant in its local formulation can be categorised as relatively non-toxic based on the scale proposed by Lorke [11]. This study shows that the highest concentration of the aqueous extract can reduce the fluid intake in rats. Reduction in fluid consumption may be responsible for the loss in body weight of the animals in the $500 \mathrm{mg} / \mathrm{kg}$ bw.

Increased or decreased organ weight (either absolute or relative) has been observed as a sensitive indicator of organ toxicity by known toxicants [5]. The aqueous extract of Cassytha filiformis did not produce any demonstrable toxic effects to the relative organ weights of the liver, spleen, testes, and kidneys. $500 \mathrm{mg} / \mathrm{kg}$ bw of the aqueous extract drastically reduced the relative weights of the lungs and heart while $250 \mathrm{mg} / \mathrm{kg}$ bw produced a marked increase in the relative weight of the heart. The extract might

Table 1: Relative Organ Weights of Rats at Termination of Treatment with Aqueous Whole Extract of C. filiformis

\begin{tabular}{lcccc}
\hline & \multicolumn{4}{c}{ Relative organ weight (g\%) body weight } \\
\cline { 2 - 5 } Organ & Control & $\mathbf{2 5 0}$ & $\mathbf{5 0 0}$ & $\mathbf{1 0 0 0}$ \\
\cline { 2 - 5 } Treatment $(\mathbf{m g} / \mathbf{k g ~ b w})$ \\
\hline Liver (NS) & $3.59 \pm 0.42$ & $3.22 \pm 0.55$ & $3.65 \pm 0.46$ & $3.80 \pm 0.28$ \\
\hline Heart & $0.41 \pm 0.06^{\mathrm{b}}$ & $0.42 \pm 0.05^{\mathrm{b}}$ & $0.24 \pm 0.16^{\mathrm{a}}$ & $0.43 \pm 0.03^{\mathrm{b}}$ \\
\hline Lungs & $0.77 \pm 0.17^{\mathrm{ab}}$ & $0.79 \pm 0.22^{\mathrm{b}}$ & $0.52 \pm 0.21^{\mathrm{a}}$ & $0.65 \pm 0.62^{\mathrm{ab}}$ \\
\hline Spleen (NS) & $0.49 \pm 0.59$ & $0.43 \pm 0.89$ & $0.40 \pm 0.08$ & $0.46 \pm 0.12$ \\
\hline Testes (NS) & $2.48 \pm 0.23$ & $2.33 \pm 0.14$ & $2.20 \pm 0.31$ & $3.65 \pm 0.46$ \\
\hline Kidneys (NS) & $3.59 \pm 0.42$ & $3.33 \pm 0.36$ & $3.65 \pm 0.46$ & $3.80 \pm 0.28$ \\
\hline Values are means \pm S.E.M for $N=6$ & & & \\
Mean data on the same row carrying the same superscript do not differ significantly from each other $(P>0.05)$ \\
\hline
\end{tabular}


Table 2: Effect of Aqueous Whole Extract of C. filiformis on the Haematograms of Rats at Termination of Treatment

\begin{tabular}{|c|c|c|c|c|}
\hline \multirow[b]{3}{*}{ Haematograms } & \multicolumn{4}{|c|}{ Haematological values } \\
\hline & \multicolumn{4}{|c|}{ Treatment (mg/kg bw) } \\
\hline & Control & 250 & 500 & 1000 \\
\hline $\mathrm{Hb}(\mathrm{g} / \mathrm{dl})(\mathrm{NS})$ & $12.50 \pm 2.29$ & $13.62 \pm 3.07$ & $13.43 \pm 1.73$ & $13.70 \pm 1.08$ \\
\hline PCV (\%) (NS) & $37.50 \pm 6.89$ & $43.33 \pm 5.16$ & $41.67 \pm 5.16$ & $41.68 \pm 2.58$ \\
\hline WBC $\times 10^{9} / /(\mathrm{NS})$ & $6.23 \pm 1.45$ & $5.33 \pm 1.15$ & $5.72 \pm 1.14$ & $5.37 \pm 0.85$ \\
\hline $\mathrm{RBC}\left(\times 10^{9} / I\right)(\mathrm{NS})$ & $4.57 \pm 0.71$ & $4.83 \pm 1.10$ & $3.67 \pm 0.42$ & $4.23 \pm 0.87$ \\
\hline $\mathrm{MCH}(\mathrm{PC})(\mathrm{NS})$ & $32.13 \pm 13.95$ & $32.15 \pm 11.72$ & $32.15 \pm 6.35$ & $32.85 \pm 5.87$ \\
\hline $\mathrm{MCHC}(\mathrm{g} / \mathrm{dl})(\mathrm{NS})$ & $33.35 \pm 0.08$ & $30.03 \pm 8.15$ & $32.93 \pm 0.59$ & $27.15 \pm 10.91$ \\
\hline $\operatorname{MCV}(f l)(N S)$ & $8.33 \pm 1.08$ & $7.93 \pm 2.20$ & $9.03 \pm 1.34$ & $9.80 \pm 1.85$ \\
\hline Platelets $\left(\times 10^{9}\right)(\mathrm{NS})$ & $4.20 \pm 0.79$ & $4.07 \pm 1.57$ & $3.93 \pm 0.47$ & $4.52 \pm 1.05$ \\
\hline \multicolumn{5}{|c|}{ Values are means \pm S.E.M for $N=6$} \\
\hline \multicolumn{5}{|c|}{ NS: Mean data on the same row do not differ significantly from each other $(P>0.05)$} \\
\hline \multicolumn{5}{|c|}{ Haemoglobin concentration $(\mathrm{Hb})$} \\
\hline \multicolumn{5}{|c|}{ packed cell volume (PCV) } \\
\hline \multicolumn{5}{|l|}{ white blood cell (WBC) } \\
\hline \multicolumn{5}{|c|}{ red blood cell $(R B C)$} \\
\hline \multicolumn{5}{|c|}{ mean cell haemoglobin $(\mathrm{MCH})$} \\
\hline \multicolumn{5}{|c|}{ mean cell haemoglobin concentration (MCHC) } \\
\hline mean cell volume (MCV) & & & & \\
\hline
\end{tabular}

\section{Table 3: Effect of Aqueous Whole Extract of C. filiformis on Differential Counts of Rats}

\begin{tabular}{|c|c|c|c|c|}
\hline \multirow[b]{3}{*}{ Haematograms } & \multicolumn{4}{|c|}{ Differential Leucocytes Counts } \\
\hline & \multicolumn{4}{|c|}{ Treatments (mg/ kg bw) } \\
\hline & Control & 250 & 500 & 1000 \\
\hline Nuetrophils (NS) & $45.17 \pm 6.68$ & $46.33 \pm 9.03$ & $49.83 \pm 5.91$ & $52.17 \pm 6.34$ \\
\hline Lymphocytes (NS) & $49.33 \pm 6.25$ & $47.67 \pm 11.55$ & $44.33 \pm 4.80$ & $44.67 \pm 6.44$ \\
\hline Monocytes (NS) & $4.17 \pm 2.79$ & $3.33 \pm 2.25$ & $3.67 \pm 3.88$ & $2.67 \pm 1.21$ \\
\hline Eosinophils (NS) & $1.33 \pm 5.51$ & $1.33 \pm 1.21$ & $2.17 \pm 1.47$ & $0.50 \pm 1.23$ \\
\hline Basophils (NS) & $0.00 \pm 0.00$ & $0.00 \pm 0.00$ & $0.00 \pm 0.00$ & $0.00 \pm 0.00$ \\
\hline \multicolumn{5}{|c|}{ Values means \pm S.E.M for $N=6$} \\
\hline
\end{tabular}

have caused cellular damage to the heart and lungs relative to other organs as well as the kidneys. Therefore, the circulatory and excretory system of animals exposed to the medicinal plant may be adversely affected.

Certain medicinal herbal preparations or convectional drugs or chemicals adversely affect various blood components $[15,8]$. Decrease or increase in cell counts and depletion of plasma constituents or their elevation beyond reference range could equally demonstrate haematoxicity [5]. The aqueous whole plant extract did not affect the haematograms of the rats in a manner that would suggest adverse effects on their bone marrow, which is a source of recticulocytes. Some herbal remedies equally have hepato and nephro toxic effects $[10,3]$. Damage to these organs often results in the elevation of clinical chemistry parameters such as serum enzymes and analytes; some serum enzymes include aspartate aminotransferase (AST) and alanine aminotransferase 


\section{Table 4: Effects of Aqueous Whole Extract of C. filiformis on Certain Plasma}

Biochemical Parameters at Termination of Treatment

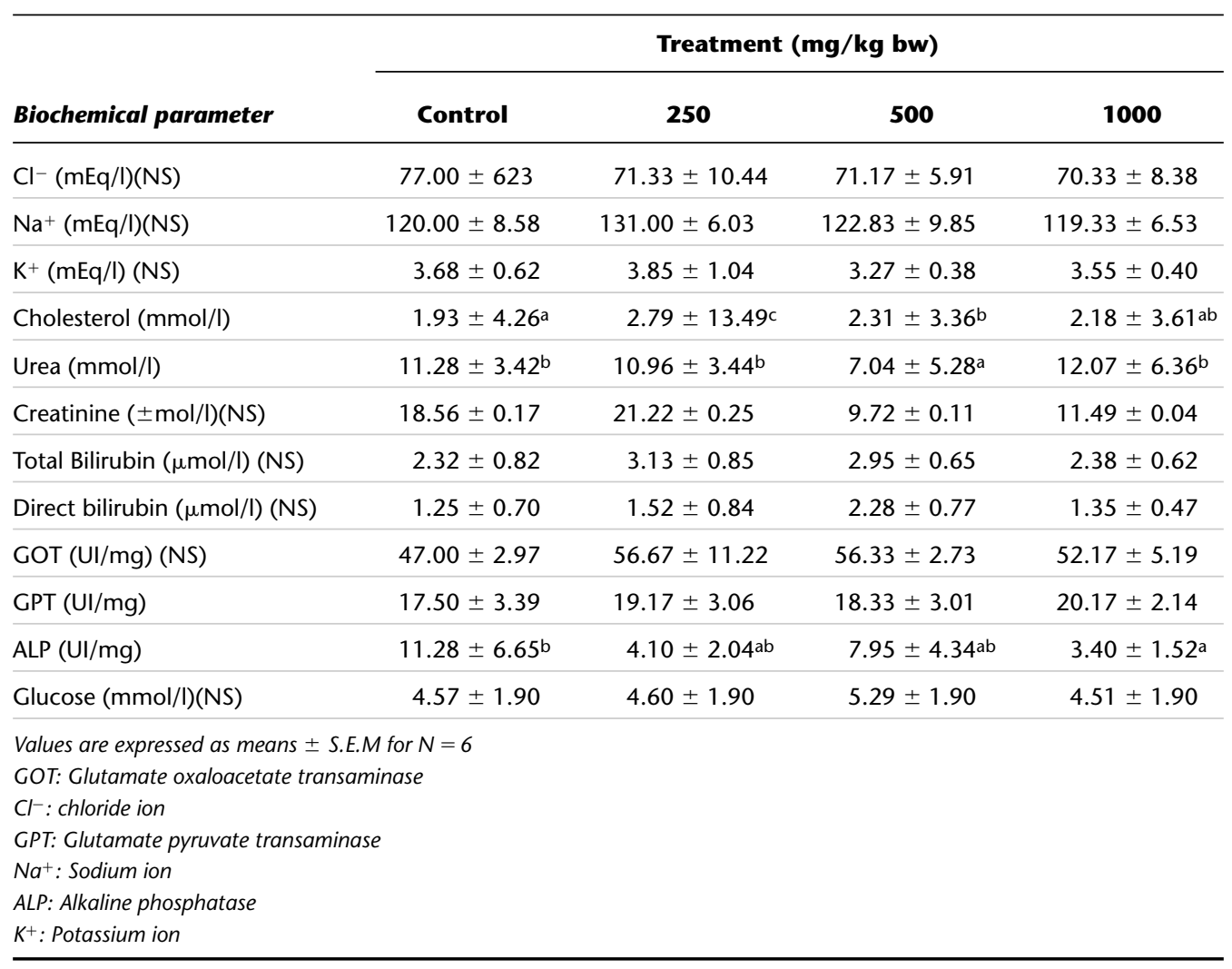

(ALT), and some analytes include total and conjugated bilirubin, urea, and creatinine $[1,3,7,14]$. The significant reduction in alkaline phosphatase levels by administration of the aqueous extract shows that no possible cholestasis occurred at the dose levels tested since a rise in plasma ALP level is usually a characteristic finding in cholestatic liver disease [4]. This was further confirmed by the fact that there were no significant changes in glutamate oxaloacetate transminase, glutamate pyruvate transminase, and total and direct bilirubin levels. This possibly suggests that the hepatic capacity to excrete bilirubin was not impaired by the extract.

The insignificant difference in urea levels between some treated groups and the control group and the reduced levels of urea in the $500 \mathrm{mg} / \mathrm{kg}$ bw group probably indicate that the extract did not interfere with the renal capacity to excrete the metabolite. It may also be a reflection of the preserved renal integrity of treated rats [4].

All the drug exposed rats showed an elevation in cholesterol levels. This is a concern because a high level of cholesterol contributes to cardiovascular diseases. Therefore, a patient on prolonged administration of the medicinal plant extracts may stand the risk of arteriosclerosis. Also, the extract may not effect glucose levels in normal hosts, but it may lower glucose levels in hyperglycaemic states. Our study could be regarded as a preliminary investigation, necessitating further studies to establish the mechanisms of toxicity of aqueous extract of $C$. filiformis. In particular, a hispathological assessment would help to obtain valuable information on microscopic pathologic abnormalities in the heart, lungs, kidney, and other organs. When administered at normal therapeutic doses, our findings have shown that aqueous extract of $C$. filiformis is not likely to produce severe toxicological effects on selected organs, biochemical indices, and haematological markers in rats.

The authors have no potential financial conflicts of interest to report.

\section{REFERENCES}

1. Adedeji, AO. Rapid Interpretation of Routine Clinical Tests. Zaria, Nigeria: Asekome and Company, 1992. 1981. pp. 16-31.

2. Abdullahi M, Mohammed G and Abdulkadir NU. Medicinal and Economic Plants of Nupeland. Bida, Nigeria: Jube - Evans Books and Publications; 2003. pp. 140.

3. Akdogan M, Kilinc I, Oncu M, Karaoz E and Delibas N. Investigation of Biochemical and Histopathological Effects of Mentha piperita L and Mentha spicata L on Kidney Tissue in Rats. Human and Experimental Toxicology. 2003;22:213-219. 
4. Aniagu SO, Nwinyl FC, Akumka DD, Ajoku GA, Dzarma S, Izebe KS, et al. Toxicity Studies in Rats Fed Nature Cure Bitters. African Journal of Biotechnology. 2005;4(1):72-78.

5. Dioka C, Orisakwe OE, Afonne OJ, Agbasi PU, Akumka $\mathrm{DD}$, Okonkwo CJ and et al. Investigation into the haematologic and hepatoxic effects of rinbacin in rats. Journal of Health Science. 2002;48(5):393-398.

6. Garba, (2000). Traditional Medical Practitioner. Zaria, Kaduna State, Nigeria.

7. Kallner A and Trydry N. IFCC Guidelines to the Evaluation of Drug Effects in Clinical Chemistry. Scandinanan Journal of Clinical and Laboratory Investigations

1989;195:1-29.

8. King DJ and Kelton JG. Heparin - Associated Thrombocytopaenia. Annuals of Internal Medicine.

\section{4;100:535-540.}

9. Leclercq JQ, Hoet S, Block S, Wautier MC and Stevingny C. Studies on Cassytha filiformis from Benin: Isolation, Biological Activities and Quantification of Aporphines. Proceedings of Bioresources Towards Drug Discovery and Development 2004; pp. 81-106.

10. Lin TJ, Su CC, Lan CK, Jiang DD, Tsai JL and Tsai MS. Acute Poisonings with Breynia officinalis - An Outbreak of Hepatoxicity. Journal of Clinical Toxicology. 2003;41: 591-594.

11. Lorke D. A New Approach to Acute Toxicity Testing. Archives of Toxicology. 1983;54:275-287.

12. Natural Institute of Environmental and Health Sciences. [webpage on the Internet]. Respect for life [updated 2002; cited 2006 Nov 11]. Available from: http://www.nih.org/ factsheets.html

13. Neuwinger HD. African Traditional Medicine. A Dictionary of Plants' Use and Applications. Medical Pharmacology. 2000;99:1-12.

14. Stonard MD and Evans GO, (1995). Clinical Chemistry. In Ballantyne B, Marrs T, Turner P (eds). General and Applied Toxicology. Macmillan Press. London. pp. 247.

15. Synder R, Lea GW, Kocsis JJ and Witner, CM (1977). Bone marrow Depressant and Leuconogenic Actions of Benzene. Life Science. 21:1709-1722.

16. World Health Organization. Basic OECD Principles of Good Laboratory Practice. [updated 2004; cited 2006 Nov 11] http://www.who.int/tdr/publications.

17. Zhu M, Low KT and Loung P. Protective effects of Plant formula on ethanolic-induced gastric lesions in rats. Phytotherapy Research. 2002;16: 276-280. 